\title{
Osnutak i djelovanje Galerije slika grada Karlovca i djelovanje Galerijskog odjela Gradskog muzeja Karlovac
}

\section{Škrtić, Antonija}

Source / Izvornik: Institucije povijesti umjetnosti : zbornik 4. kongresa hrvatskih povjesničara umjetnosti, 2019, 65 - 71

Conference paper / Rad u zborniku

Publication status / Verzija rada: Published version / Objavljena verzija rada (izdavačev PDF)

https://doi.org/10.31664/z4khpu.08

Permanent link / Trajna poveznica: https://urn.nsk.hr/urn:nbn:hr:254:779478

Rights / Prava: Attribution 4.0 International/Imenovanje 4.0 međunarodna

Download date / Datum preuzimanja: 2023-04-26

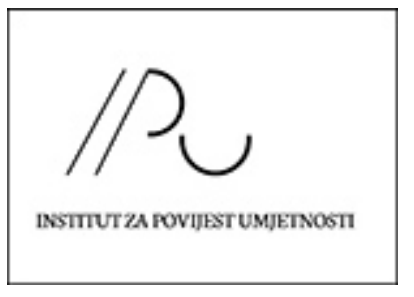

Repository / Repozitorij:

PODEST - Institute of Art History Repository

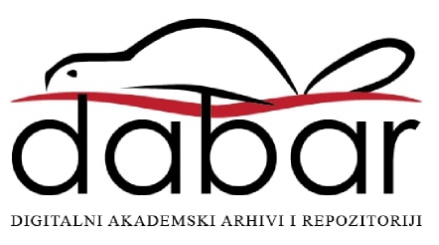




\section{Osnutak i djelovanje Galerije slika grada Karlovca i djelovanje Galerijskog odjela Gradskog muzeja Karlovac}

\section{Uvod}

Galerija slika grada Karlovca osnovana je ı2. srpnja ı945. godine kao prva galerijska ustanova u Hrvatskoj nakon Drugoga svjetskog rata. ${ }^{1}$ Od I952. do I954. godine provedeno je spajanje Galerije slika i Gradskog muzeja, stručno zasnovana 1952. godine zaslugom prve direktorice i kustosice Ivane Vrbanić.

\section{Osnutak Galerije slika grada Karlovca ${ }^{2}$}

Sa završetkom Drugog svjetskog rata i na karlovačkom području dogodile su se brojne društvene i gospodarske promjene, koje su izmijenile fizionomiju grada. Galerija slika grada Karlovca osnovana je u srpnju ig45. godine zalaganjem Adele Pintar ${ }^{3}$ i Nikole Dragarića. ${ }^{4}$ Izvorna građa o tom događaju potvrđuje već poznate činjenice, ali otkriva i prešućivane pojedinosti. ${ }^{5}$ Najraniji izravni spomen Galerije izvještaj je Gradskoj skupštini za vrijeme od 6 . svibnja do II. srpnja I945. godine, u kojem piše da se pristupilo „prikupljanju slika na dobrovoljnoj bazi od građanstva” te da je „ista galerija slika smještena u kući A. Dobryja". ${ }^{6}$ Neizravni spomen Galerije datiran je mjesec i pol kasnije, točnije 3o. kolovoza i945. godine, kada Nikola Dragarić u molbi za namještenje u gradskoj službi ističe da obavlja dužnost čuvara Gradske galerije slika. ${ }^{7}$ Arhivske podatke potvrdila je i Adela Pintar u razgovoru vođenu 20oo. godine, kada je izjavila da je u rodni Karlovac stigla s Jugoslavenskom armijom Io. svibnja I945. godine. I sama iz dobrostojeće obitelji, bila je upoznata s imovinskim stanjem karlovačkih obitelji te svjesna opasnosti od raznošenja njihove imovine, u prvom redu knjiga i umjetnina. Stoga je II. ili I2. svibnja I945. godine od Gradskoga narodnog odbora, zajedno s Nikolom Dragarićem, zatražila i dobila dozvolu za ulazak u stanove „odbjeglih ustaša” za koje je pretpostavila da bi mogli posjedovati umjetnine, tj. slike, te su se Nikola Dragarić i ona, uz pravnu pomoć „advokata” Srećka Ćopa, ubrzo našli na terenu. ${ }^{8}$ Ta se izjava doduše razlikuje od

\section{Antonija Škrtić}

Gradski muzej Karlovac antonija.druzak@gmk.hr https://orcid.org/oooo-oooI-7325-26ro
I Tijekom poraća osnovane su galerije u Dubrovniku, Zadru i Rijeci.

2 Osnivač Galerije slika grada Karlovca je do I947. godine Okružni narodni odbor Karlovac, potom ju preuzima Gradski narodni odbor. U spisima se koristi naziv Galerija slika Okružnog narodnog odbora, odnosno Galerija slika Gradskog narodnog odbora. Službeni naziv je Galerija slika grada Karlovca. Gradski muzej Karlovac (dalje: GMK), Spisi Galerije slika Gradskog narodnog odbora (dalje: Spisi Galerije) 22/47, 9. srpnja I947.

3 Adela Pintar (I9I7.-2003.), djelatnica u kulturi i diplomaciji. Referent prosvjetnog odjela Izvršnog Gradskog narodnog odbora do I6. siječnja I946. godine kada postaje službenica Ministarstva vanjskih poslova. Državni arhiv Karlovac (dalje: DAKA), Spisi Gradskog narodnog odbora Karlovac za I945 i I946. godinu (dalje: Spisi GNO) II8I/46, Vejvodina brzojavka Adeli Pintar.

4 Nikola Dragarić (I899.-I98I.) slikar, scenograf i djelatnik u kulturi u Karlovcu. Uz Galeriju, zaslužan za osnivanje Karlovačkog kazališta I945. godine.

5 Spisi GNO r945. i I946., Zapisnici sjednica Izvršnog odbora Gradskog narodnog odbora, I945.-I949. i I949. - I952. (dalje: Zapisnici IO GNO), Zapisnici sjednica Gradske skupštine I. saziva, I945-- I947. (dalje: Zapisnici Gs), Spisi Galerije

6 DAKA, Zapisnici Gs, izvještaj od 6. svibnja. do II. srpnja I945.; GMK, Spis Galerije, 7/46.

7 DAKA, Spisi GNO, 6236-Io369, 3o. kolovoza I945.

8 Zapis razgovora s Adelom Pintar, 25. listopada 2000. Razgovarala: Antonija Škrtić. 
izjave koju je dala u sudskom sporu između Gradskog muzeja Karlovac i Đure Bajera: ${ }^{\text { }}$ "U to vrijeme u prosvjetnom odjelu Gradskog narodnog odbora odlučeno je da se formira galerija iz razloga što je bilo umjetnina u stanovima koji su u to vrijeme bili rekvirirani. Dobila sam zadatak i javila se $u$ komandu mjesta koja mi je dala popis rekviriranih stanova, kako bih izvršila obilazak i utvrdila o kojim se umjetninama radi i sastavila popis. Kao stručna osoba pomagao mi je Dragarić Mika. Ja sam na tom poslu ostala do siječnja mjeseca I946. godine. Pojedinačno o slikama ne mogu reći ništa, ali u to vrijeme radilo se o prilično dobrom fondu."10

Pri sabiranju umjetnina vođen je popis prikupljenoga, koji dosad nije pronađen. Djelovanje Komisije za skupljanje i očuvanje kulturnih spomenika i starina (KOMZA) na području Karlovca nije istraženo. Sigurno je, dakle, samo da su Adela Pintar i Nikola Dragarić u ime nove vlasti u Karlovcu prikupljali umjetnine i knjige prije osnutka komisije, a Dragarić i nakon toga. ${ }^{11}$ Adela Pintar potvrdila je da su prikupljene umjetnine bile smještene na prvi kat kuće Dobry ${ }_{12}^{12}$ gdje su u prizemlju živjele dvije kćeri iz obitelji Dobry, dok im je majka Thea Dobry ${ }^{13}$ bila u zatvoru. ${ }^{14}$

\section{Privatna zbirka slika obitelji Dobry}

Izgradnju spomenute kuće naručio je tvorničar Antun Dobry (Mlada Boleslav, 4. svibnja I899. - Jasenovac, I944.) kao zakoniti zastupnik maloljetnih kćeri Božene (I927.) i Branke (I930.). On se početkom I920-ih godina iz Češke doselio u Zagreb, gdje se I925. godine u evangeličkoj crkvi vjenčao s Marijom Terezijom Theom Penkala. U drugoj polovini I93o-ih godina s obitelji se nastanjuje u Karlovcu kao suvlasnik tkalačke radionice Roltex-proizvodnja finih vunenih tkanina. ${ }^{15}$ Antun Dobry je I944. godine prokazan vlastima kao davatelj crvene pomoći partizanima ${ }^{16}$ te odveden u koncentracijski logor Jasenovac, gdje je r944. godine nestao. ${ }^{17}$ Obitelj Dobry posjedovala je zbirku slika, pa su prostorije na prvom katu kuće projektirane da bi odgovarale izlaganju zbirke u svrhu potrebe reprezentacije. ${ }^{18}$ Nakon ulaska partizana $u$ Karlovac Thea Dobry prokazana je kao suradnica neprijatelja i zatvorena, a njihova je kuća tijekom svibnja i lipnja i945. godine privremeno stavljena pod prinudnu upravu i upotrijebljena kao prostor u koji su se prikupljale slike iz napuštenih stanova, ali i „dobrovoljno” darovane slike (sl. I). Dosadašnjim istraživanjem nije utvrđena konfiskacija kuće i zbirke, a osnovni zakon o eksproprijaciji donesen je I947. godine ${ }^{19}$ pa pretpostavljamo da se u pitanju kuće i zbirke Dobry radilo o privremenom stavljanju pod prinudnu upravu. Budući da se Thea Dobry u kasno ljeto i jesen I945. godine obranila od optužbi, Gradski narodni odbor odobrio je isplatu stanarine za smještaj Galerije slika za razdoblje od I. srpnja do 2I. rujna I945. godine u iznosu od goo dinara mjesečno. ${ }^{20}$ Thea Dobry s kćerima potkraj I946. godine seli u Rijeku, a poslije u München.
9 Predmet spora su bile dvije slike Anke Krizmanić. Spor je I988. godine zaključen u korist Gradskog muzeja Karlovac, da bi bio ponovno otvoren tijekom devedesetih godina i r999. godine zaključen u korist Đure Bajera.

Io GMK, Spis Gradskog muzeja Karlovac, 48/I-93, primljeno 9. lipnja 1993 .

II GMK, Spisi Galerije, 4/46, 22. kolovoza I946. godine.

I2 Kuća se nalazi u Ulici Frana Kurelca 3.

I3 Rođena II. ožujka I9o5. godine u Zagrebu kao treće od četvero djece izumitelja Eduarda Slavoljuba Penkale (I87I.-- 1922.) i Emilije Stoffregen. Supruga Antuna Dobryja.

I4 Prema riječima Adele Pintar, zahvaljujući zalaganju Srećka Čopa i nje osobno.

I5 DAKA, Registar Zanatstvo II (I936.-I945.); MIRA KOLAR DIMITRIJEVIĆ, Privredni razvoj Karlovca između dva rata u: Karlovac I579-ı979, (ur.) Đ. Zatezalo, T. Majetić, K. Miholović, Karlovac, I979., 227-239; NINO PERIĆ, ŽELJKO LAURIĆ, Obrtništvo u Karlovcu, Karlovac, Udruženje obrtnika grada Karlovca, ı997, 60.

I6 Kazivanje prof. Bischof i Aleksandera Forenbachera.

I7 http://www.jusp-jasenovac.hr/Default.aspx?sid=76ı 8 (posjećeno 2. studenoga 20I2.)

I8 GMK, Spisi Galerije, I7/47, Podaci o Galeriji slika za Odjel za kulturu i umjetnost za Ministarstvo prosvjete, 3 o. travnja I947.

I9 TOMISLAV ANIĆ, Normativni okvir podržavljenja imovine u Hrvatskoj/Jugoslaviji I944.-I946., u: Časopis za suvremenu povijest, 39, I (2007.), 25-62, Službeni list FNRJ 28 (I947.).

20 DAKA, Zapisnici IO GNO, 2I. rujna I945., 20. 
Prema sačuvanim izvješćima i popisima ${ }^{21}$ zbirka obitelji Dobry sastojala od ukupno 34 slike, uglavnom suvremenih hrvatskih autora. ${ }^{22}$ Thea Dobry je prije odlaska iz Karlovca ponudila Galeriji slika na otkup cijelu zbirku, no Nikola Dragarić je u obzir za otkup uzeo jedanaest umjetnina. S obzirom da Okružni narodni odbor nije imao financijskih mogućnosti, angažiralo se Ministarstvo prosvjete NR Hrvatske te je kupljeno osam umjetnina uz uvjet da umjetnine postanu sastavni dio inventara Moderne galerije u Zagrebu, ali da budu stalno izložene u Galeriji slika u Karlovcu. ${ }^{23}$ S odlaskom Thee Dobry iz Karlovca u Galeriji slika grada Karlovca ostalo je ukupno 44 slike, što prema Nikoli Dragariću nije bilo dovoljno za „pregled galerije", ${ }^{24}$ pa je pokrenuo akciju posudbe slika od Moderne galerije, do čega je i došlo 23. travnja I947. godine. ${ }^{25}$

Kuća Dobry je kao solidno građen i atraktivan prostor ubrzo postala predmet brojnih aspiracija, kojima se kustos-čuvar Nikola Dragarić uspijevao oduprijeti zahvaljujući podršci Ministarstva. Usprkos tome, Galerija slika je od prosinca I947. godine do svibnja I948. godine premještena u iznajmljeni prostor u prizemlju zgrade Zemaljske banke u Ulici Petra Zrinjskog 24, a nakon toga, od početka svibnja I948. godine do I95I. godine, u zgradu Doma kulture. U kuću Dobry vratila se nakon 8. kolovoza I95I. godine te je u njoj bila smještena sve do I965. godine. ${ }^{26}$
2I GMK, Spisi Galerije, 2/47,6/47 s prilogom popisa slika otkupljenih po Ministarstvu prosvjete /B/.

22 M. Kraljević, Djevojka s pourćem; V. Bukovac, Akt; M.Cl. Crnčić, Zimski krajolik, ulje i Sanjarenje, ulje; I. Tišov, Iz Maksimira, ulje; V. Becić, Povratak, ulje i Motiv s Neretve, ulje; Lj. Šestić, Motiv s Kupe, ulje, Motiv Karlovca, ulje i Autoportret, ulje; M. Trepše, U parku, ulje; M. Jama, Krajolik, ulje; O. Mujadžić, Vezilja, Muslimanski interieur, ulje, Majka, ulje i Na izvoru, ulje; E. Vidović, Splitski motiv; M. Krušlin, Jesenski motiv, ulje; T. Krizman, Mrtua priroda, ulje; nepoznati autor, Portret starca, ulje; J. Crnobori, Portret, pastel, Djevojka u naslonjaču, pastel, Djevojka sa gitarom, ulje; M. Makanec, Korana, ulje; S. Aralica, Žena u crvenom, ulje; G. Likan, Konjske trke, ulje; A. Kuman, Seoske kuće, ulje; L. Kralj Međimurec, Muški akt, ulje; M. Rački, Slapovi, akvarel; [S.] Titirinov, Seoski motiv, akvarel i Kraj Sofije, akvarel. Slika M. Kraljevića Djevojka s pourćem vraćena je Thei Dobry radi prodaje 3. lipnja 1946. godine (GMK, Spisi Galerije, 2/46, 3o. lipnja I946.), a slika V. Bukovca Akt, ulje, Ig. srpnja I945. godine (GMK, Spisi Galerije, 3/46, 6. kolovoza I946.).

23 GMK, Spisi Galerije, I2/47, 24. ožujka I947.

24 GMK, Spisi Galerije 4/47, 29. siječnja I947.

25 GMK, Spisi Galerije, I5/47.

26 GMK, Spis Galerije, 26/5I, I2. rujna I95I.

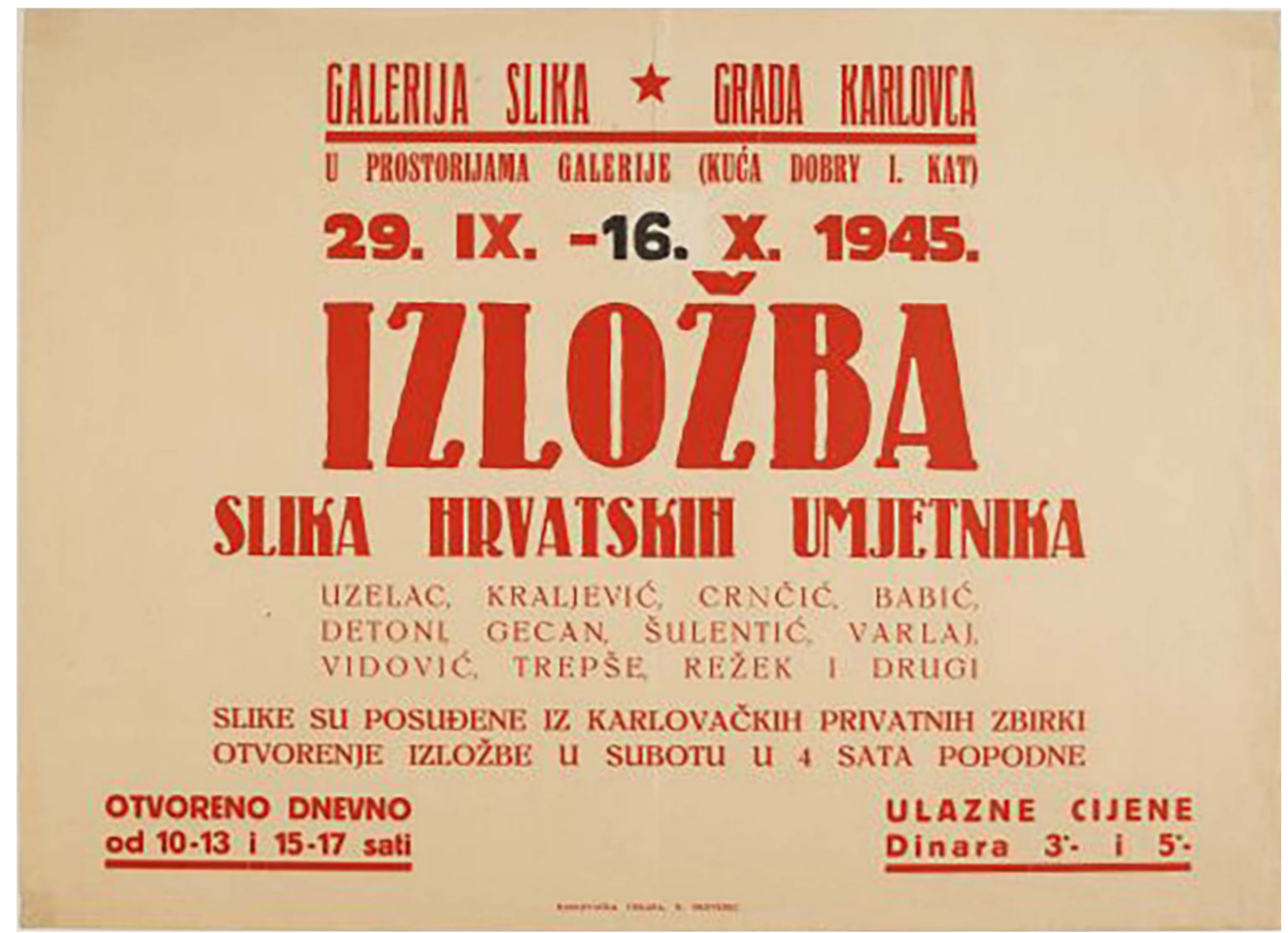

Slika I

Plakat za Izložbu slika hrvatskih umjetnika, I945. Gradski muzej Karlovac, foto: Goran Vranić 


\section{Djelovanje Galerije slika}

Izložbena djelatnost Galerije slika u lokalnim okvirima postala je prepoznatljiva zahvaljujući suradnji s karlovačkim slikarima. Njome je popularizirano likovno izražavanje među mladima te je takvo ozračje iznjedrilo nekoliko akademskih slikara i stvorilo temelj za razvoj likovnog amaterizma.

Stalni se postav Galerije slika zbog problema s prostorom i zbirkom u nekoliko navrata postavljao i skidao, a koncepcijska osnova bio mu je prikaz razvoja modernog i suvremenog nacionalnog slikarstva, slikama iz vlasništva Galerije slika i posuđenima od Moderne galerije i Gradskog narodnog odbora. Antun Bauer $^{27}$ prigodom izložbe karlovačkih slikara I948. godine (sl. 2) tako ističe: „Konačni smještaj ove Galerije u odgovarajuće prostorije prijeka je kulturna potreba za grad Karlovac. Ostala naša provincijska mjesta osnivaju uz najveće žrtve i velike troškove svoje gradske muzeje, pa bi i Karlovac, koji je bez velike muke i truda došao do vrlo lijepog materijala za Galeriju slika, mogao se bar pobrinuti za dolične prostorije, te bi se i time učinio kraj seljakanju te Galerije, koja nije baš imala mnogo sretnih dana." ${ }^{28}$ Ivana Vrbanić svoje je pak stručno viđenje Galerije slika grada Karlovca i njezinih perspektiva objavila u članku u Karlovačkom tjedniku..$^{29} \mathrm{U}$ tekstu daje stručnu analizu stanja galerije, ističe potrebu rješavanja problema prostora za obavljanje djelatnosti te donosi viziju razvoja kojemu bi osnovni cilj trebao biti edukativnoga karaktera, s naglaskom na sabiranje i prezentaciju Karasova opusa i drugih autora koji su podrijetlom ili radom vezani za grad Karlovac, što kao do danas određuje djelatnost Galerijskog odjela Gradskog muzeja Karlovac.

\section{Formiranje zbirke}

Glavnina otkupa u razdoblju od I945. do I952. godine vezana je za prigodu povremenih izložbi održanih u Galeriji slika. Nadležno ministarstvo od I95o. godine sve češće pokrajinskim galerijama daruje umjetnine te na taj način u nekoliko navrata u zbirku ulaze vrijedna umjetnička djela. ${ }^{30}$

Postojanje inventara Galerije slika grada Karlovca posredno je potvrđeno od I947. godine nadalje, no sustavno inventariziranje usklađeno sa standardima muzejske struke započela je tek Ivana Vrbanić. Galerija slika grada Karlovca od I945. do I954. godine, u skladu s imperativima muzejske djelatnosti poslijeratnog vremena, osim izložbe stalnog postava organizirala je i veći broj povremenih izložbi. Izložba djela Vjekoslava Karasa, kojom je Ivana Fadejev-Vrbanić javnosti otvorila vrata Gradskog muzeja Karlovca, organizirana je upravo radi popularizacije muzejske djelatnosti unutar lokalne zajednice. ${ }^{31}$
27 Antun Bauer (I9ıı.-200o.) zaslužni muzealac, sakupljač, arheolog, povjesničar i donator. Osnivač i ravnatelj Gipsoteke (I937.), Arhiva za likovne umjetnosti (I944.) i Muzejskog dokumentacijskog centra (I955.). 28 Naše novine, 4. lipnja I948., 2.

29 Karlovački tjednik, I4. kolovoza I953., 3.

30 Djela: P. Šimage i F. Mraza (I950.); B. Ružića, P. Šimage, K. Mijića, S. Glumca, A. Krupe, A. Zupe, V. Ercegović (I952.); A. Šojata, J. Vanište, J. Resteka, I. Dulčića, Z. Gradiša, N. Reisera, H. Gudca, M. Pejića, (I953.). GMK, Spisi Galerije, 58/53, 26. lipnja I953.

3I ANKA SIMIĆ-BULAT i IVANA VRBANIĆ-FADEJEV, Vjekoslav Karas, katalog izložbe slika, Karlovac, GMK, I954. 
Plakat za Prvu godišnju tj.

proljetnu izložbu karlovačkih

autora, I948.

Gradski muzej Karlovac,

foto: G. Vranić

\section{GALERIJA SLIKA $\succsim$ GRADA KARLOVCA}

PRIREDUJE U DOMU KULTURE

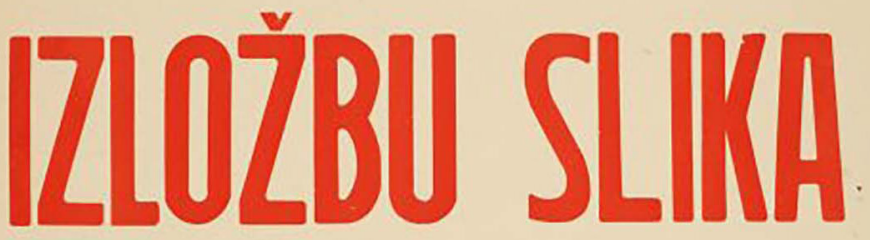

IZL A $\mathbf{Z}$ U:

Dragarōe Nißrola

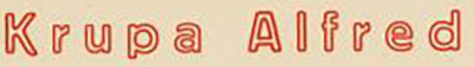

Pečenes VDaho

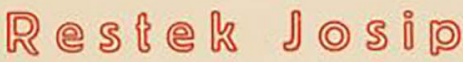

OTVORENJE 23. V. u 10 sati,

A tRAJE DO 6. VI. 1948.

KATALOG _ DIN, ULAZNINA 5 DIN, GRUPE 2 DIN

OTVORENO OP 9-19 sat 


\section{Djelovanje Galerije slika nakon I964. godine}

Uoči šezdesete godišnjice Gradskog muzeja Karlovac, početkom rujna I964., sudskim putem raskinut je ugovor između tadašnjeg vlasnika kuće Dobry i Muzeja te se Galerija do I. prosinca trebala iseliti, što je ipak bilo prolongirano do 30 . lipnja I965. godine, kad su slike drvenim kolicima prevezene u Muzej.

Prema urbanističkom planu uređenja Novog centra autora Milana Bijelića i Želimira Žagara (I960.--1964.) Skupština općine Karlovac, u partnerstvu s tvrtkom Auto-Hrvatska iz Zagreba, I967. godine sagradila je izložbeni paviljon u tadašnjoj Marinkovićevoj ulici, također prema projektu spomenutih arhitekata. Galerijski postav otvoren je 20. srpnja I967. godine, a tada je promovirano i novo ime Galerije slika koja se od tada prema odluci Muzeja naziva Galerija Vjekoslav Karas. U izložbenom prostoru od $300 \mathrm{~m}^{2}$ bilo je izloženo 5I slika na platnu, 3I grafika i četiri skulpture. Ubrzo se, međutim, uvidjelo da stakleni plašt i slaba toplinska izolacija zgrade nisu prikladni za izlaganje umjetnina, pa je prostor prodan tvrtki Auto-Hrvatska, a Grad je I975. godine odlučio tri stotine metara južnije sagraditi novu zgradu prema idejnom projektu arhitekata Želimira Žagara i izvedbenom Stanka Kočevara. U novoj zgradi prva je izložba otvorena 25. svibnja I976. godine.

Uz Ivanu Vrbanić, kao kustos Galerije u vremenu od ı964. do I967. godine radio je povjesničar umjetnosti Antun Strzalkowski, od I973. do I994. godine kustos je povjesničar umjetnosti i likovni amater Petar Skutari (Budva, I I. veljače I93I. - Karlovac, I4. studenoga I999.), koji je bio angažiran na izgradnji nove zgrade, $u$ kojoj je riješeno pitanje čuvaonice za zbirku ali nažalost ne i izložbenog prostora za stalni postav. Zbog nezadovoljavajućih mikroklimatskih uvjeta za dugotrajno izlaganje slika zgrada od početka služi kao izložbeni prostor za povremene likovne, ali i ostale povremene muzejske izložbe. Budući da je istraživanje i sređivanje fotodokumentacije, hemeroteke i plakata o galerijskim i muzejskim izložbama iz tog vremena u tijeku, ukratko napominjemo da je Petar Skutari u njoj realizirao brojne monografske i didaktičke izložbe likovne umjetnosti, bavio se stručnim istraživanjima i prezentacijom opusa Vjekoslava Karasa i drugih slikara aktivnih u Karlovcu u I9. stoljeća. Pokrenuo je likovnu manifestaciju lokalnog karaktera na kojoj su zajednički izlagali likovni amateri i akademski likovni umjetnici nazvanu Karlovačke likovne jeseni, a r979. godine, u povodu obilježavanja 40o. obljetnice grada Karlovca, manifestaciju Biennale akvarela Jugoslavije, koja je od I979. do I989. održana šest puta. Godine I99I. manifestacija je zbog političkih okolnosti obustavljena, a kao svojevrsna suma rada na popularizaciji akvarela u suvremenom slikarstvu na području bivše države organizirana je izložba BAJ - Trgovi, na kojoj su izloženi akvareli nabavljeni za galerijsku zbirku tijekom održavanja Biennala. 


\section{Zaključak}

Djelovanje Galerije slika grada Karlovca (ı945--ı952.) karakterizira entuzijazam njezina kustosa-čuvara Nikole Dragarića, nestašica novca, nedostatak i nesigurnost prostora te činjenica da je Galerija slika opstala zahvaljujući potpori iz Zagreba i suradnji s karlovačkim slikarima. Razina svijesti o važnosti kvalitetnoga stručnog galerijskog djelovanja bila je vrlo niska, pa osnivač tek sporadično odgovara na potrebe Galerije. Osnutak i djelovanje Galerije slika ukazuju na širu problematiku djelovanja stručnih institucija-muzeja i galerija u manjim hrvatskim sredinama toga vremena.

\section{(ㄷ) (i)}

Osnutak i djelovanje Galerije slika grada Karlovca i djelovanje Galerijskog odjela Gradskog muzeja Karlovac/ Antonija Škrtić / CC BY / 4.o

DOI: https://doi.org/Io.3I664/z4khpu.o8 